Basic Neuroscience

\title{
An MRI-compatible caloric stimulation device for the investigation of human vestibular cortex
}

\author{
Sebastian M. Frank ${ }^{\mathrm{a}, \mathrm{b}}$, Mark W. Greenlee ${ }^{\mathrm{b}, *}$ \\ a Department of Psychological and Brain Sciences, Dartmouth College, Hanover, NH, USA \\ ${ }^{\mathrm{b}}$ Institute for Experimental Psychology, University of Regensburg, Germany
}

\section{H I G H L I G H T S}

- We present a new closed-loop MR-compatible delivery system for caloric vestibular stimulation (CVS) during fMRI.

- Chilled and hot water are repeatedly circulated simultaneously to left and right ear canals for robust CVS.

- In-scanner eyetracking reveals the onset of caloric nystagmus within the stimulation period.

- Functional MRI on a sample of 13 participants reveals activations in parieto-insular vestibular cortex (PIVC) and related cortical areas.

- This CVS delivery system can be combined with optic flow motion stimuli to study multisensory interactions underlying self-motion perception.

\section{A R T I C L E I N F O}

\section{Article history:}

Received 10 March 2014

Received in revised form 14 July 2014

Accepted 15 July 2014

Available online 23 July 2014

\section{Keywords:}

Caloric vestibular stimulation

fMRI

Self-motion perception

Vestibular cortex

Caloric nystagmus

\begin{abstract}
A B S T R A C T
Background: Self-motion perception involves the integration of vestibular, visual, somatosensory and other sensory cues. The neural responses to caloric vestibular stimulation (CVS) in humans have been investigated with functional magnetic resonance imaging (fMRI).

New method: We developed an fMRI-compatible, bithermal caloric stimulation device for repeated CVS. Tempered water is pumped via a closed-loop tube-system to one or both ear canals. Water temperature transmits to the surface of the ear canal via a small glass-pod. For our purposes we used hot $\left(47-49{ }^{\circ} \mathrm{C}\right)$, cold $\left(5-7.5^{\circ} \mathrm{C}\right)$, or warm for baseline $\left(30-32.5^{\circ} \mathrm{C}\right)$. The pods are integrated in the MRI ear protection and connected to water influx and efflux tubes. With our device we can apply multiple vestibular stimulation and baseline trials consecutively. Control measurements indicate that the applied temperatures are stable across trials. MRI-signal differences due to water flow and water temperature are restricted to the area surrounding the pod and are unlikely to intrude into brain tissue.

Results: Vestibular stimulation with our device elicits caloric nystagmus when no central fixation is presented. We validated our system by conducting a CVS experiment during fMRI-scanning. Participants indicated the presence or absence of a self-motion sensation. Periods of self motion yielded activation in the cortical vestibular network including putative human parieto-insular vestibular cortex (PIVC).

Comparison with existing methods: Our closed-loop device eliminates many problems associated with caloric stimulation during fMRI.

Conclusions: Our device allows researchers to explore neural responses to CVS and those evoked by combined sensory stimulation.
\end{abstract}

(C) 2014 Elsevier B.V. All rights reserved.

\section{Introduction}

The vestibular sense is a primary sensory system that provides us with information about our current position and acceleration in

\footnotetext{
* Corresponding author at: University of Regensburg, Universitaetsstrasse 31, 93053 Regensburg, Germany. Tel.: +49 941943 3281; fax: +49 9419433233.

E-mail addresses: mark.greenlee@psychologie.uni-regensburg.de, mark.greenlee@ur.de (M.W. Greenlee).
}

space. It closely interacts with the visual system for the perception of self motion that arises when we move through our surroundings (Britten, 2008; DeAngelis and Angelaki, 2012). The vestibular sensors lie in the inner ear next to the cochlea of the auditory system in a structure called the bony labyrinth. The vestibular part of the labyrinth contains two otoliths (utricle and saccule) for the sensation of linear acceleration and gravity and three semicircular canals filled with endolymph for detection of angular acceleration. Afferents of the vestibular nerve propagate the information to the vestibular nuclei in pons and medulla, to posterolateral thalamus, 
and finally to cortex. This projection is referred to as the vestibulothalamo-cortical pathway (see Dieterich and Brandt, 2008). Other vestibular pathways project to the cerebellum, to medulla and pons in the brainstem, and to the spinal cord.

In primates several cortical areas have been identified for vestibular processing (see DeAngelis and Angelaki, 2012; Guldin and Grüsser, 1998; Lopez and Blanke, 2011, for reviews). Parieto-insular vestibular cortex (PIVC; Chen et al., 2010; Grüsser et al., 1990; Guldin and Grüsser, 1998) is often considered a core unit of the cortical vestibular system (e.g. Dieterich and Brandt, 2008; Lopez and Blanke, 2011).

Studies in monkeys used inertial motion of a platform where the animal was seated in a Bárány chair or on a moving platform for vestibular stimulation (see Chen et al., 2010; DeAngelis and Angelaki, 2012). A similar technique was applied in humans for psychophysical vestibular testing (Probst et al., 1995) and during simultaneous electroencephalographic recordings (Loose et al., 1999). The possibility to move the participant is greatly restricted inside the scanner (besides illusionary induced self motion via visual motion cues, e.g. Cardin and Smith, 2010) and thus most studies involving positron emission tomography or functional magnetic resonance imaging (fMRI) used caloric, galvanic, or auditory vestibular stimulation (Lopez et al., 2012a). Of all three techniques caloric stimulation is the most frequently used approach (see Lopez et al., 2012a; zu Eulenburg et al., 2012). It also plays an important role in clinical vestibular function testing (Brandt and Strupp, 2005; Dieterich and Brandt, 2008).

Caloric vestibular stimulation (CVS) uses hot and/or cold temperatures of water or other media that are applied to the ear canal and induce circulatory movements of the endolymph primarily in the horizontal semicircular canal located closest to the ear canal (Wuyts et al., 2007). Previous imaging studies provided temperature stimulation by means of direct injection of tempered water (Deutschländer et al., 2002; Dieterich et al., 2003; Suzuki et al., 2001), tempered air (Naito et al., 2003), or cooled nitrogen gas (Fasold et al., 2002) into the ear canal. Increasing the temperature of the endolymph in the horizontal canal evokes current movement toward the ampulla, a dilatation of the canal that contains the sensory neurons, whereas cold has the opposite effect (Bárány, 1907). Endolymph flow toward the ampulla depolarizes the sensory cells in the horizontal semicircular canals, thereby increasing firing in the vestibular nerve. If the flow is directed away from the ampulla the sensors are hyperpolarized and vestibular nerve firing is diminished compared to the firing rate during resting (baseline).

An advantage of the caloric approach is the stimulation of a specific vestibular sensor that evokes percepts of self motion in distinguishable directions. In our fMRI-experiment about which we will report below participants described the induced sensation of self motion as rotation in the roll- or yaw-plane (see also Deutschländer et al., 2002; Dieterich et al., 2003; Fasold et al., 2002) and predominantly indicated self motion away from the side of cold stimulation. Drawbacks of CVS, especially with tempered water, are that circulating water can lead to artifactual changes in the MRI-signal (Lobel et al., 1998), the problem of collecting the used water while the participant is still inside the scanner (see Deutschländer et al., 2002; Dieterich et al., 2003; Suzuki et al., 2001), and delays associated with temperature transduction within the temporal bone (Barnes, 1995).

Galvanic stimulation applies electrical current to the left and right neck mastoid processes and excites the entire vestibular nerve. This approach provides strong vestibular stimulation and elicits sensations of self motion, however, since all vestibular afferents are activated, the sensation is not merely experienced as simple rotation of the head to the left or right in the roll/yaw-planes, but is more complex (Smith et al., 2012; Stephan et al., 2005). Brief auditory sounds of high intensity can lead to stimulation primarily in the saccular otolith, however, so far only few studies applied this technique for vestibular stimulation during functional imaging (e.g. Schlindwein et al., 2008).

We aimed to construct a caloric stimulation device that is compatible with the MRI-scanner environment while overcoming some of the previously mentioned problems of this technique. Our device enables us to perform multiple, consecutive stimulations with the same or different temperatures in either one or both ears (bithermal caloric stimulation, Anderson, 1995). It is a closed-loop system that avoids problems associated with water collection inside the scanner (see Mast et al., 2006, for a similar approach in a behavioral experiment).

In the following we will report on technical details of this new caloric stimulation device. We found that MRI-signal differences due to water circulation and water temperature are restricted to the immediate vicinity of the stimulation pods in the outer ear. CVS with our system elicited nystagmus when no central target was presented. We also conducted a vestibular localizer in 13 participants during fMRI-scanning. In this experiment participants indicated the presence or absence of self-motion sensations to the left or right. Based on previous findings we expected to find activation in the cortical vestibular network including putative human PIVC during periods of perceived self motion and concurrent CVS with our device.

\section{Methods}

\subsection{Vestibular stimulation device}

Our vestibular stimulation device allows for bithermal caloric stimulation using hot and cold distilled water. The water remains inside a closed-loop system and does not enter the ear canal. Fig. 1a shows the scheme of the stimulation apparatus. Images of the actual device are shown in Figs. 1b-d and 2. The following equipment is required to build the system: three plastic barrels, two temperature sensors, two mini-pumps, eight plastic tubes, a switching device to stimulate left and right ears with different water temperatures, two rigid glass-pods (each connected to a water influx and efflux tube) that are integrated in the left and right side of the MRI ear protection, and a plastic relay plate with a belt that is worn by the participant. In the following we will discuss every piece of the device in more detail and explain the mode of operation for the entire system.

Two barrels that can hold 251 each are used to store hot and cold water (see 1 in Fig. 1a and b). Electronic thermometers (Hanna Instruments US, Woonsocket RI, USA) were placed in each barrel. Water was heated to $\sim 50^{\circ} \mathrm{C}$ (hot) in the one barrel or cooled with crushed ice to $\sim 0{ }^{\circ} \mathrm{C}$ (cold) in the other barrel before starting vestibular stimulation. We measured temperatures continuously with thermal sensors and kept temperatures at constant levels throughout each vestibular experiment. This was done by refilling the respective barrel with either hot water or crushed ice. The third barrel had a volume of 501 and it collected all returning water (5 in Fig. 1a and b). Two mini-pumps (Barwig Wasserversorgung, Bad Karlshafen, Germany) achieving a pressure of 0.6 bar each were placed deep inside the hot- and cold-water barrels. They are connected to two plastic tubes (red and blue solid lines on the left in Fig. 1a, diameter: $11 \mathrm{~mm}$ ) and transport the tempered water to the switching device ( 2 in Figs. $1 \mathrm{a}$ and $\mathrm{b}$ and $2 \mathrm{a}$ ). The switching device was located on a table in the scanner control room (distance between barrels and switching device: $1.5 \mathrm{~m}$ ).

The plastic switching device was designed to allow for unilateral or bilateral stimulation with hot, cold, or warm. Same or different temperatures can be applied to the left and right ear canals at the same time. The device (see Fig. 2a for details) is custom-built and 
essentially consists of four manually operated switches that open or close the flow of water in the tube passing through the switch (each tube is $4 \mathrm{~mm}$ in diameter). Two switches on the left side of the panel open or close a value that allows or prevents the flow of hot and cold water to the left ear. Two switches on the right side provide control over hot and cold water flow to the right ear. The two tubes with hot and cold water coming from the barrels split up in two tubes each on the switching panel (in a plastic bifurcation) and connect to the switches for hot left and hot right as well as cold left and cold right, respectively. Directly adjacent to the four switches is a plastic manifold through which the tubes pass. Each channel of the manifold is labeled at each of the four switches informing the user about the water temperature and the side of stimulation for each switch (labeled "warm" and "cold" in Fig. 2a for left and right ears). The switching panel is $24 \mathrm{~cm} \times 20 \mathrm{~cm}$ in size. It is made of durable plastic and has contact grip pads on the back side to assure stability during usage. We will describe the operation of the switches for stimulation with different temperatures in the next section.

For the application of hot water left, all but one switch (for the tube carrying hot water to the left ear) have to be closed. For the application of hot water left and cold water right (as shown in Fig. 1a, viewed from in front of the head), the switches for hot left and cold right remain open while switches for cold left and hot right are closed. Finally, a baseline temperature (warm) is achieved by opening all switches (i.e. hot left, cold left, hot right, cold right). This is because tubes for hot and cold conjoin at a later stage (at the relay plate worn by the participant, see 4 in Figs. $1 \mathrm{a}$ and b and $2 \mathrm{~b}$ ). If hot and cold tubes for one side are both open, the differently tempered water will intermix at the relay plate to yield a baseline temperature of $\sim 30-32^{\circ} \mathrm{C}$. This temperature was selected since it could be achieved by mixing hot and cold tempered water and it was close to body temperature. During baseline stimulation participants did not indicate temperature sensations that were noticeably different from no-stimulation. Also, sensations of self motion occurred only rarely during warm water flow (see vestibular experiment below). Thus, we think that the chosen temperature of warm water provided an appropriate baseline condition with little stimulation of the vestibular system. During baseline trials, no additional tactile stimulation occurred, because the glass pods did not change in size during water circulation, contrary to earlier CVS devices (Falconer and Mast, 2012; Lopez et al., 2012b).

The four plastic tubes ( 3 in Fig. 1a and b; displayed as solid lines in red for hot, blue for cold, and gray for closed, i.e. no circulating water, in Fig. 1a) passed through the waveguide and entered the scanner room. The tubes are wrapped inside insulating black foam sheaths (see 3 in Fig. 1b). There were two separate insulated sleeves for hot and cold water tubes. The two insulating sleeves containing the tubes are tied together with cable binders. This allows the four tubes to form a dense configuration that is good for handling. At the same time this configuration leads to slight cooling of the hot and warming of the cold water, respectively, despite the individual insulation (see temperature measurements later). With a distance of approx. $8.2 \mathrm{~m}$ the tubes were attached to the relay plate at the waist of the participant (4 in Fig. $1 \mathrm{a}$ and b; Figs. $1 \mathrm{~d}$ and $2 \mathrm{~b}$ for more details) that was fastened prior to lying down on the scanner bench. As mentioned previously hot and cold tubes conjoin at the relay plate at the participant's waist so that only one instead of two tubes leads to each ear (Fig. 2b). This final tube had a length of $0.7 \mathrm{~m}$ (diameter: $4 \mathrm{~mm}$ ) and terminates in a small glass pod (Figs. 1c and $2 \mathrm{c}$ for details). The pods were manufactured from a glass tube by welding together the end of the tube. The glass pod had a plastic attachment (shaped like a ring) at the bottom with one input and one output hole for water influx and efflux, respectively. Another plastic tube ( $4 \mathrm{~mm}$ diameter, no foam shielding, $10.5 \mathrm{~m}$ long) was attached to the glass pod and drains the used water back to the scanner control room (see below). The glass pod and the two adjacent tubes were integrated into the ear protection and adjustable in position and length thus making the system compatible with differently sized ear canals. We instructed participants to position the pods as deeply as possible in each ear canal without creating any discomfort. Water is pumped into the pods and leads to the heating or cooling of the glass and the skin surface surrounding the pod. We expected this to stimulate predominantly the horizontal semicircular canals due to their close location to the ear canal.

Two tubes (dotted red and blue lines in Fig. 1a; see also Fig. 2b) drain the used water from every ear through the waveguide to the 50-1 collecting barrel located in the scanner control room (5 in Fig. 1a and b). We stored all water in this barrel and reused it for later experiments. Approximately 0.51 of water circulated on each trial that lasted $30 \mathrm{~s}$ (see vestibular experiment later).

As can be seen in Fig. 1d the stimulation device fits well with the limited space on the MRI-bench. All participants in the current experiment confirmed that neither the pods in the ear protection nor the relay plate and waistline belt nor the water tubes bothered them during the experiment.

We used bithermal stimulation with conditions of hot left and simultaneously cold right, cold left and simultaneously hot right, and warm simultaneously in both ears. Hot-cold trials served as caloric stimulation trials. Moderate temperature (warm) was used to create a baseline condition with little vestibular stimulation. Compared to caloric stimulation by means of direct injection of water, tempered air, or nitrogen gas into the ear canal our stimulation device provides a milder temperature stimulus; therefore we decided to use bithermal stimulation to increase intensity of vestibular stimulation. However, our device also allows for unilateral stimulation with hot, cold, or warm for baseline and thus is suitable for the investigation of laterality effects in cortical vestibular processing (see Dieterich et al., 2003).

\subsection{Temperatures at the surface of the stimulation pod}

Outside the scanner we conducted measurements of the final temperatures of hot, cold, and warm in the stimulation pod. A metal sensor (Heraeus Sensor Technology, Kleinostheim, Germany) was attached to the outer surface of one stimulation pod and it measured the temperature with a sampling frequency of $5 \mathrm{~Hz}$. A volunteer was placed in supine position on the floor in the control room outside the scanner and he inserted the stimulation pod with the attached temperature sensor in one ear canal. Room temperatures in the control room and the scanner room were comparable (both $\sim 23^{\circ} \mathrm{C}$ ). The participant underwent three conditions with a total of 40 trials of 30 s each: 10 trials with hot, 10 trials with cold, and 20 trials with warm stimulation. As in the fMRI-experiments, hot or cold trials alternated with warm (baseline) trials.

The temperature curves for hot, cold, and warm water trials in the sensor-equipped stimulation pod are shown in Fig. 3. Three results emerge from the data: First, the device requires a temporal gradient of approximately $10 \mathrm{~s}$ duration to reach a stable steady-state level of stimulation (hot or cold). Accordingly, we later computed vestibular-related brain-activation for the $15 \mathrm{~s}$ long period of constant stimulation intensity following the initial $10 \mathrm{~s}$ ramp (indicated by the shaded gray area in the subplots of Fig. 3). Second, same and different temperatures have a very similar timecourse across trials demonstrating reliability of stimulation. Third, the final temperature of hot (Fig. 3a) is slightly lower $\left(47.5-49^{\circ} \mathrm{C}\right)$ than the temperature of hot water in the barrel $\left(50^{\circ} \mathrm{C}\right)$. Likewise cold water had a temperature of $0^{\circ} \mathrm{C}$ in the barrel, but was $\sim 5-7.5^{\circ} \mathrm{C}$ in the pod (Fig. 3b). As mentioned previously hot and cold tubes were individually insulated by black foam padding but closely tied together leading to slight heating or cooling. However, the slightly 
a)

Vestibular

Stimulation

1

2
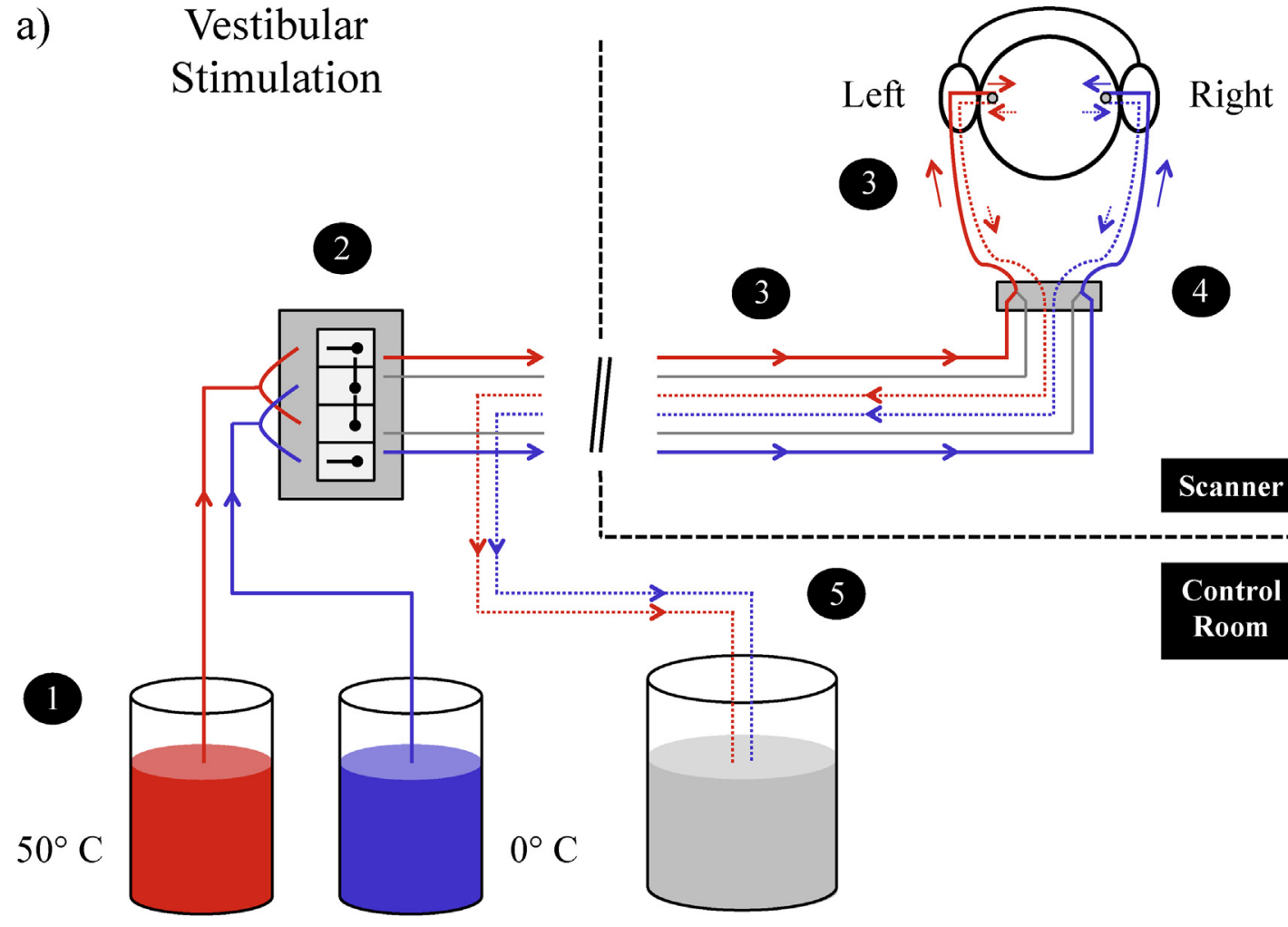

Scanner

$50^{\circ} \mathrm{C}$
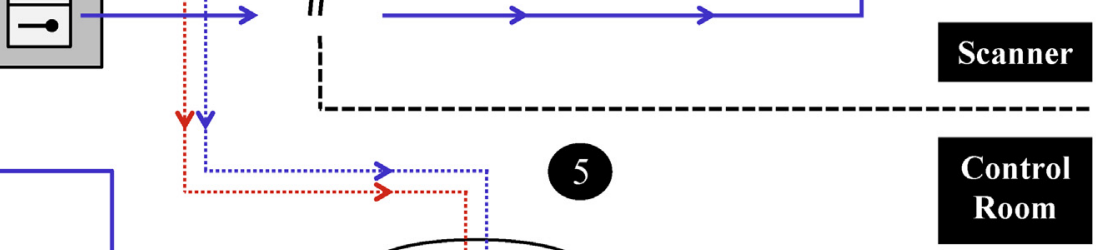

b)

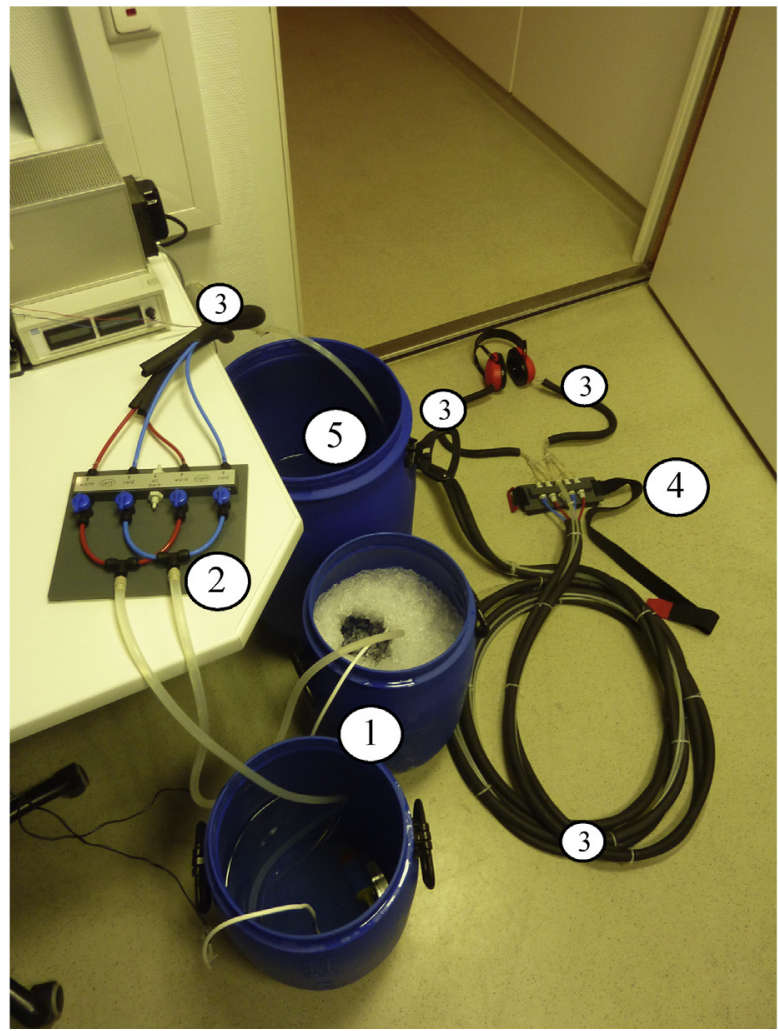

c)

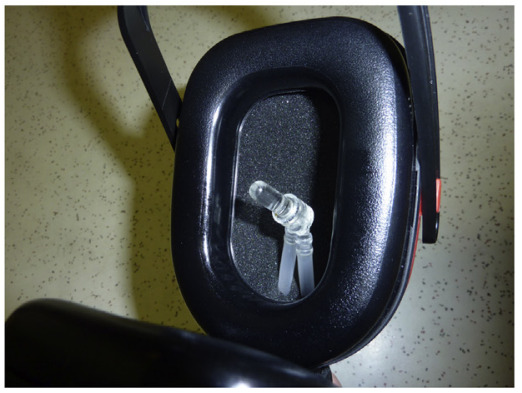

d)

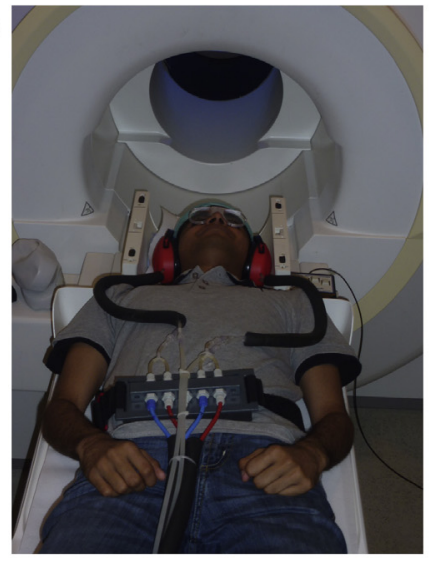

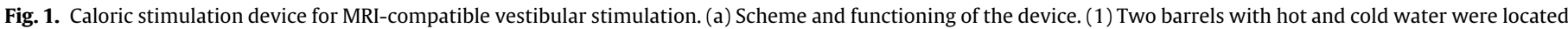

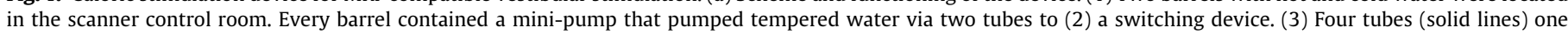

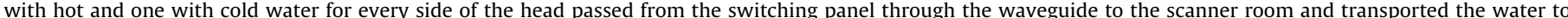

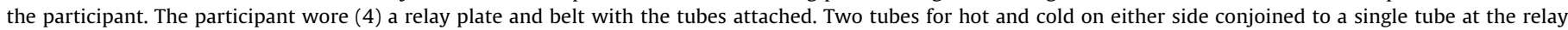

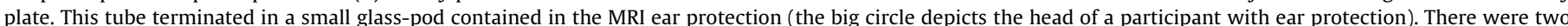

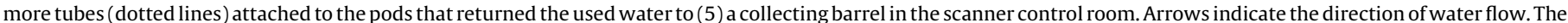


a) Switching Device

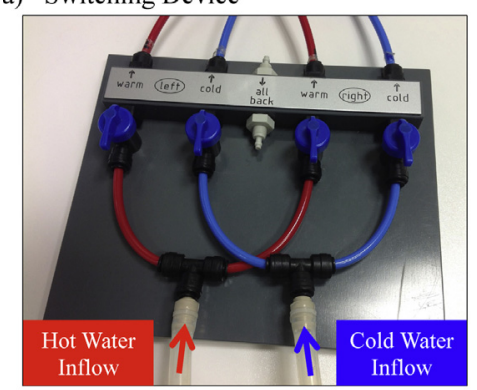

c) Stimulation Pod

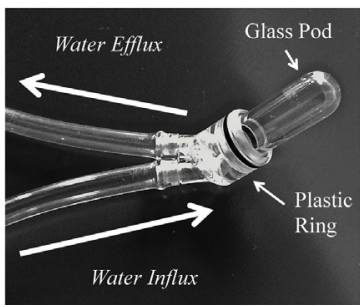

b) Relay Plate With Belt

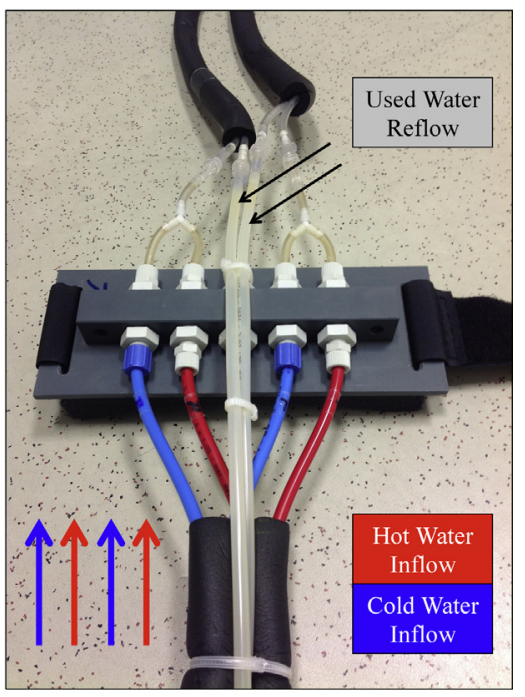

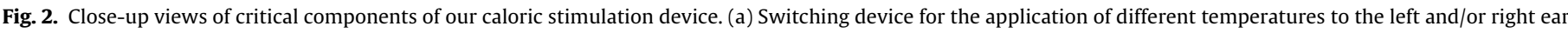

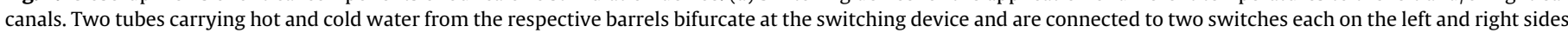

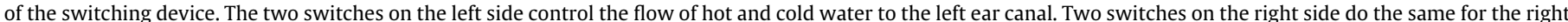

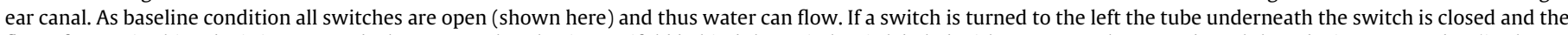

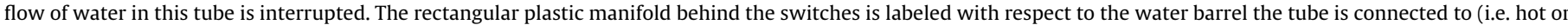

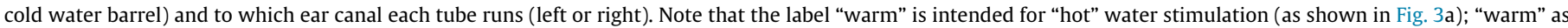

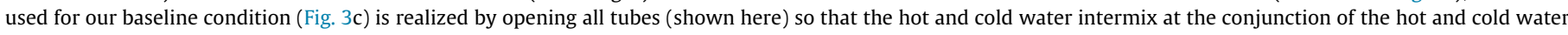

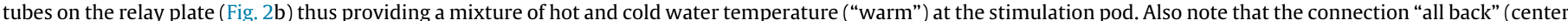

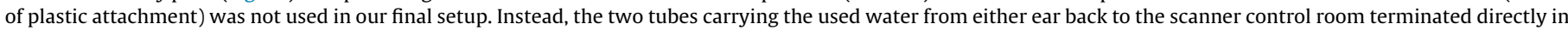

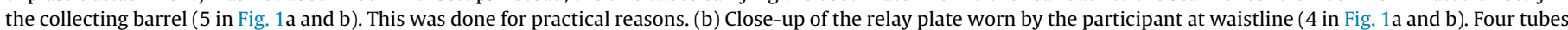

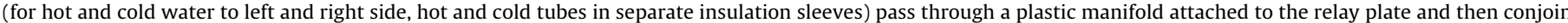

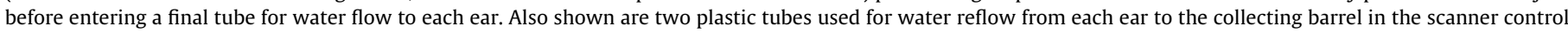

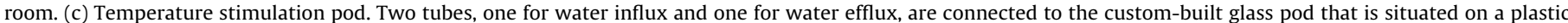

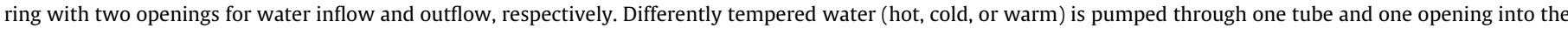

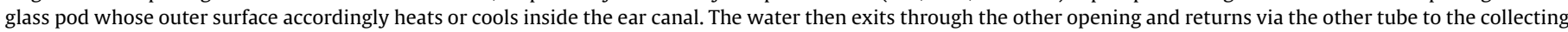

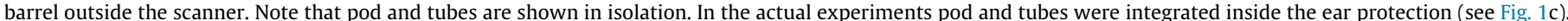
(For a color version of the figure the reader is referred to the web version of the article.)

reduced temperature of the hot water made the stimulation more comfortable for the participant and the slightly higher temperature of the cold stimulus might have helped to reduce ice-water nystagmus (Batuecas-Caletrio et al., 2009). The final temperatures in our study are in the range of temperatures used in other caloric stimulation experiments (e.g. Fasold et al., 2002; Naito et al., 2003; Suzuki et al., 2001). Our particular selection of temperatures was related to our interest in maximizing CVS within the $30 \mathrm{~s}$ trial periods.

Moderate temperature (warm, baseline) was on average $30-32{ }^{\circ} \mathrm{C}$, with slight variations depending on the temperature of the preceding trial. If a hot trial preceded the baseline trial then the average baseline temperature tended to be higher (red curves in Fig. 3c), whereas if a cold trial preceded baseline the pod temperature was slightly lower (blue curves in Fig. 3c). These differential effects on the baseline temperature were likely caused by heating or cooling of the conducting tubes in the preceding trial. Since we always used hot in one ear and cold in the other ear for vestibular stimulation, the pod temperature might have been slightly different between ears on baseline trials. However, participants did not indicate any perceived difference in temperature on baseline trials between ears. Moreover, we did not expect that slight variations of a temperature perceived as neutral (i.e. neither hot nor cold) would have substantial effects on neural activation. A workaround for this problem and a recommendation for future studies is to have longer inter-trial intervals between two caloric stimulation trials so that the baseline trial is long enough for the temperatures to stabilize at $\sim 31^{\circ} \mathrm{C}$ independently of the temperature of the preceding hot or cold trial.

We want to remark that the degree of temperature change between water in the barrels and stimulation pod is also affected by the length of the tubes and the pressure of the water pumps: Both influence how long the water remains in the tubes before arrival at the ears. Moreover, fastening together insulation sleeves containing hot and cold tubes might slightly reduce the difference between hot and cold. Thus, for each experimental setup the final temperatures at the outer surface of the glass pods should be measured in order to know how much heat loss and gain is obtained at the site of stimulation. Having two separate cable packages (one for hot tubes and one for cold tubes, not tied together) might be advantageous because in that configuration the interaction between hot and cold is reduced and the final temperatures are likely closer to those in the water containers in the scanner control room.

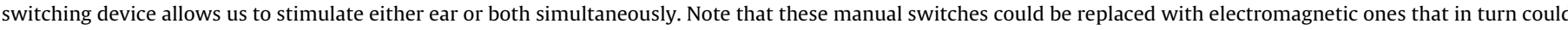

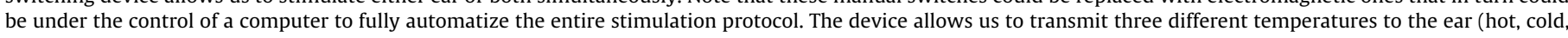

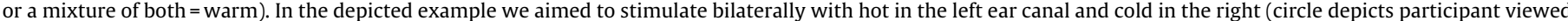

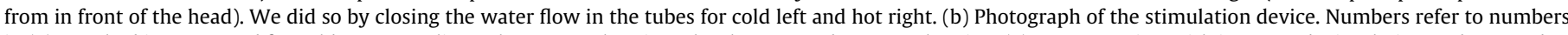

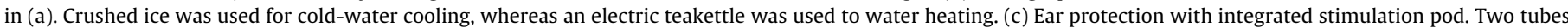

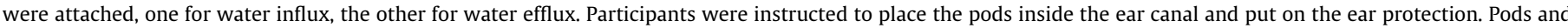

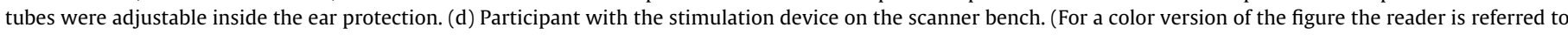
the web version of the article.) 
a)

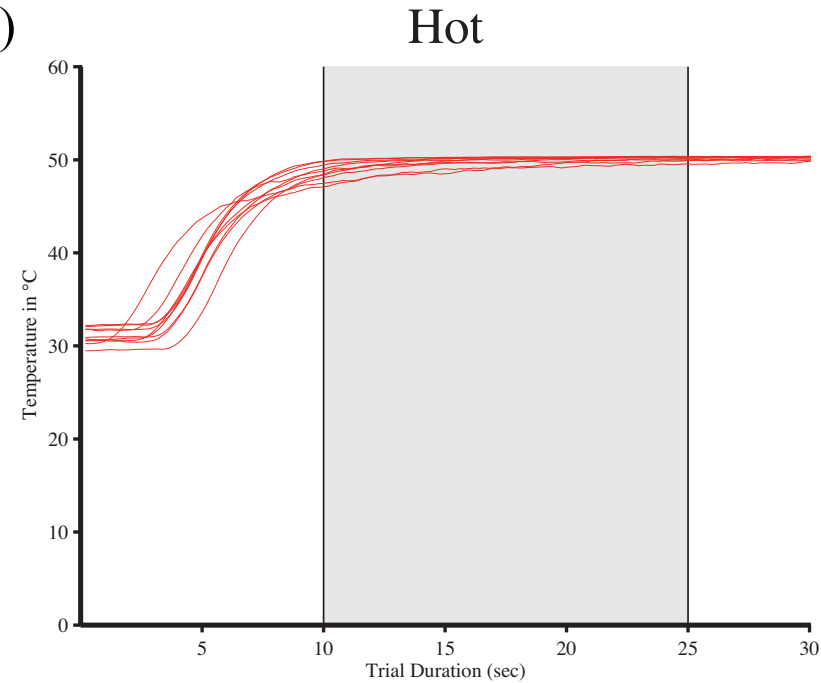

b)

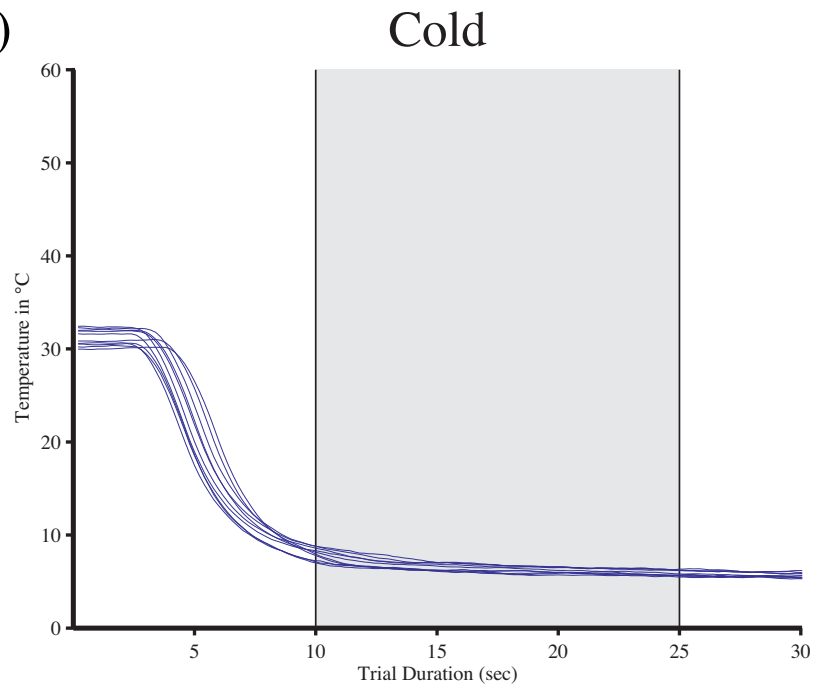

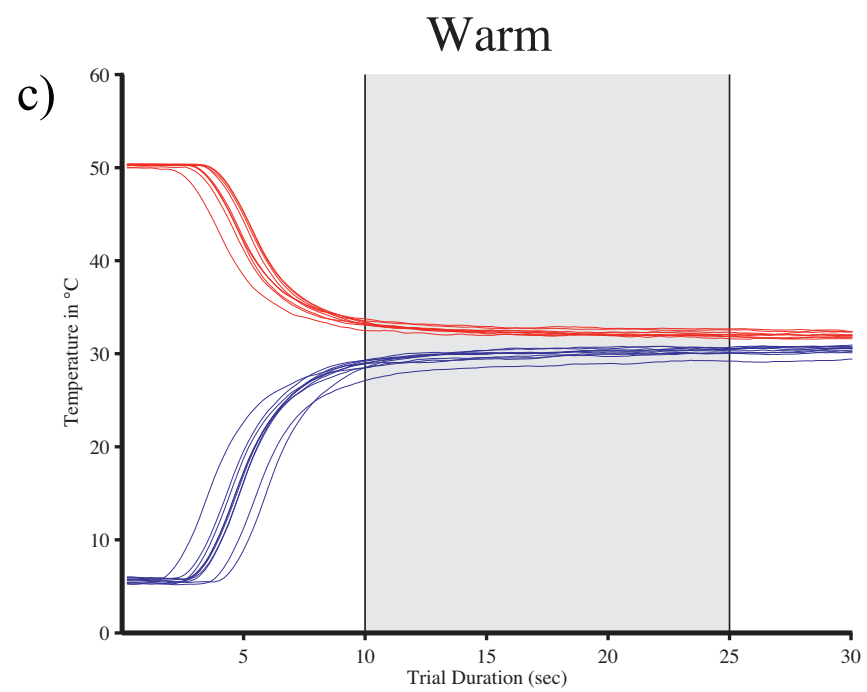

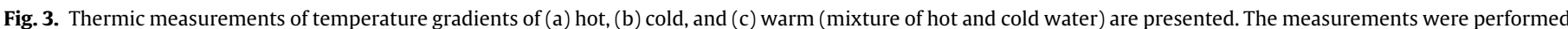

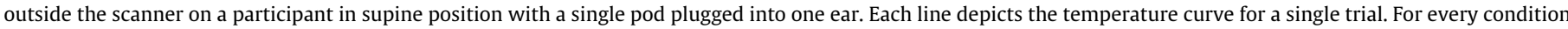

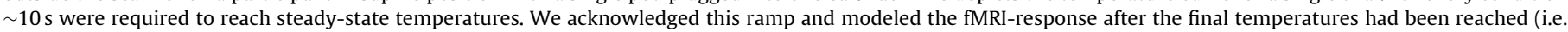

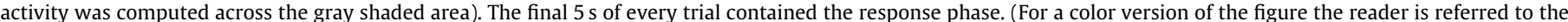
web version of the article.)

Another factor that influences the difference between final temperature at the glass pod and the temperature of the water inside the barrels is the temperature of the room where the calibration or measurement is performed. Cool room temperature will probably lead to slight cooling of the hot water at the pods. This is not a problem per se if the stimulation is performed in the same room as the calibration and if room temperature is held constant. If caloric stimulation is conducted in a different room (e.g. the MRI-scanner room) then the temperature of this room and the calibration room should be closely matched. The room temperature also has to be kept constant across different participants in order to obtain comparable temperatures for stimulation (the same is true, of course, for the water temperatures in the barrels).

\subsection{Effects of water flow and temperature on the MRI-signal}

Caloric stimulation has been reported to induce MRI-artifacts (see Lobel et al., 1998) and it is known that temperatures can modulate the MR-signal (Rieke and Butts Pauly, 2008). Thus, we examined whether those effects are also present with our stimulation and if so, whether we would find any artifacts. We performed control experiments during which we attached the ear protection with the stimulation pods to a spherical water phantom. The pods were adjacent to the outer surface of the phantom. We then conducted two measurements using time series as in our vestibular stimulation experiment: In control experiment 1 we had only two alternating conditions: warm water flow and no water flow (all pipes closed). In control experiment 2 we used a stimulation protocol with three conditions: hot left and cold right, cold left and hot right, and warm on both sides (i.e. same as in the fMRI-experiment with human participants). The stimulation was carried out inside our 3-T MRI head-scanner with a T2*-weighted gradient echo planar imaging (EPI) sequence (same parameters as in the vestibular experiment reported below). Data were analyzed using a general linear model (GLM) approach. Boxcar functions modeled each of the conditions over the full $30 \mathrm{~s}$-trial period. Thus this analysis was carried out without assuming MRI-signal delays or a specific signal-shape as in the case of blood-oxygenation-leveldependent (BOLD)-responses. All data reported are thresholded with a false-discovery-rate (FDR) of $p<0.001$. 


\subsection{Caloric nystagmus}

Nystagmus is a special type of eye movement that can occur during caloric stimulation (e.g. Deutschländer et al., 2002; Fasold et al., 2002; Naito et al., 2003; Suzuki et al., 2001). Two phases are distinguished, a so-called slow phase with a slow shift of gaze in one direction and a fast phase with a re-centering saccade in the opposite direction (this type of nystagmus is also referred to as jerk nystagmus). During caloric stimulation with hot in one ear the eyes slowly shift away from the side of hot stimulation to the contralateral side (as during head rotation to the side of hot) followed by a fast re-centering saccade in the opposite direction. In cold stimulation the slow shift is in ipsilateral direction to the side of cold (as in head rotation away from cold) followed by a saccade beating away from cold. We performed an experiment to control for the presence or absence of caloric nystagmus during CVS with and without visual fixation. An infrared-based eye-tracking system compatible with the MRI-environment (MR-Eyetracker, Cambridge Research Systems, Kent, UK) was used to sample the horizontal position of the right eye (frequency: $500 \mathrm{~Hz}$ ) while a participant underwent caloric stimulation (for details on the experimental design and trial duration see below).

\subsection{Vestibular stimulation FMRI-experiment}

\subsubsection{Participants}

Thirteen participants (five females, 18-54 years old) were scanned in the vestibular experiment. All gave informed written consent and reported no previous psychiatric, neurologic, auditory, or vestibular disease. The study was approved by the local ethics committee in accordance with the Declaration of Helsinki. For caloric stimulation we elevated participants' heads slightly in the scanner head coil (by using padding) to move the horizontal semi-circular canals in approximately vertical position (Barnes, 1995).

\subsubsection{Vestibular stimulation}

We carried out a brief sequence of caloric stimulation. This included three trials with hot water left and cold water right, three trials with cold water left and hot water right, and six trials with warm in both ears (thus duration of the vestibular run was $\sim 6 \mathrm{~min}$ ). Trials of hot-cold alternated with warm trials and the experiment started with a warm trial. The same trial sequence was used for all participants. Every 30-s trial started with an onset jitter (ranging from $500 \mathrm{~ms}$ to $1 \mathrm{~s}$ ). The scanner room was darkened and visual stimulation was kept low except for a small fixation cross at screen center. The white cross turned to red during the last $5 \mathrm{~s}$ of every trial thereby signaling to the participant to make a button-press response with respect to the presence of self motion and its prominent direction. After response registration the cross flickered briefly, thereby signaling to the participant that his response was recorded. At trial onset we switched temperatures to either hot-cold or warm and they remained unchanged until trial end. Participants were instructed to inspect for stable sensations of self motion. In particular we asked them to identify the direction of self motion. This resulted in a three-alternative forced choice task in the response phase: if participants sensed self motion to the left they pressed button 1 with their middle finger on the left buttonbox. If self motion was to the right they pressed button 2 with their index finger on the left buttonbox. In case of no self-motion sensation button 1 on the right buttonbox had to be pressed with the index finger of the right hand. We instructed participants to guess as best as they can the direction of self motion if they experienced self motion but were uncertain about its specific direction. Before the start of the experiment participants were familiarized with the different temperatures in practice trials. No participant indicated stimulation to be painful or uncomfortable due to the temperatures used. We explicitly pointed out that sensations of self motion may be evoked by every applied temperature. This was to avoid a bias toward an association of hot-cold and self motion and warm and no self-motion sensation.

\subsubsection{Scanning parameters}

A 3-T Allegra head scanner (Siemens, Erlangen, Germany) equipped with a one-channel head-coil was used for MRI-data acquisition. For each participant we collected a high-resolution T1-weighted image of the brain (160 sagittal slices) using a magnetization prepared rapid gradient echo (MP-RAGE) sequence (time-to-repeat $\mathrm{TR}=2.25 \mathrm{~s}$, time-to-echo $\mathrm{TE}=2.6 \mathrm{~ms}$, flip-angle $\mathrm{FA}=9^{\circ}$, voxel-size $=1 \mathrm{~mm} \times 1 \mathrm{~mm} \times 1 \mathrm{~mm}$, no inter-slice gap, field of view $F O V=240 \mathrm{~mm} \times 256 \mathrm{~mm}$ ) that was optimized for the differentiation of gray and white matter by sequence-parameters from Alzheimer's disease Neuroimaging Initiative project (http://adni.loni.ucla.edu). Functional images were acquired with a standard $\mathrm{T}^{*}$-weighted $\mathrm{EPI}$-sequence (40 transverse slices, $\mathrm{TR}=2.3 \mathrm{~s}, \mathrm{TE}=30 \mathrm{~ms}, \mathrm{FA}=90^{\circ}$, voxel-size $=3 \mathrm{~mm} \times 3 \mathrm{~mm} \times 3 \mathrm{~mm}$, inter-slice gap $=0.5 \mathrm{~mm}, \mathrm{FOV}=192 \mathrm{~mm} \times 192 \mathrm{~mm}$ ).

\subsubsection{Analysis}

Imaging data were analyzed in Freesurfer version 4.1 and the FSFAST toolbox (Martinos Center for Biomedical Imaging, Charlestown MA, USA). The anatomical T1-image was used to reconstruct and inflate every participant's brain (Dale et al. 1999; Fischl et al., 1999). All functional EPI-images were motioncorrected (Cox and Jesmanowicz, 1999), coregistered to the anatomical brain using the first EPI-scan of every session, smoothed with a three-dimensional Gaussian kernel (full-width at halfmaximum $=5 \mathrm{~mm}$ ), and intensity-normalized (Sled et al., 1998). We excluded the first five EPI-images (that contained blanks with instruction) in every run to secure MRI-signal equilibrium.

Preprocessed functional data were analyzed using a GLMapproach with a block-design. The GLM contained motioncorrection parameters as regressors of no interest and a scanner drift predictor taking the shape of a second order polynomial. The BOLD-response was modeled with the SPM canonical hemodynamic response function. Two predictors for activation during self motion (left + right) and no self motion were created. We included only correct trials, where participants' perception matched the physical conditions and the expected response. That is trials with hot-cold stimulation and reported sensations of self motion (independent of the direction) as well as trials with warm in both ears and absence of self motion were used. Results show that on average only two mismatching trials out of 12 trials in total had to be excluded. The BOLD-response was modeled only across the $15 \mathrm{~s}$-long period of each trial during which temperatures were at steady-state (see gray shaded area in Fig. 3). That is, neither the initial $10 \mathrm{~s}$-ramp nor the response phase $(5 \mathrm{~s})$ was modeled. A surface-based random effects-analysis was calculated to estimate group-activation during self motion vs. no self motion (or in other words: caloric stimulation vs. baseline). We expected this comparison to yield activation in vestibular cortex including the putative human homologue of primate area PIVC.

\section{Results}

\subsection{Effects of water flow and temperature on the MRI-signal}

Fig. 4a shows the results of the contrast between water circulation vs. no circulation (control experiment 1). Voxel-clusters with stronger MRI-signal during circulation of water emerged next to the left and right outer surface of the phantom (red voxels). Control 


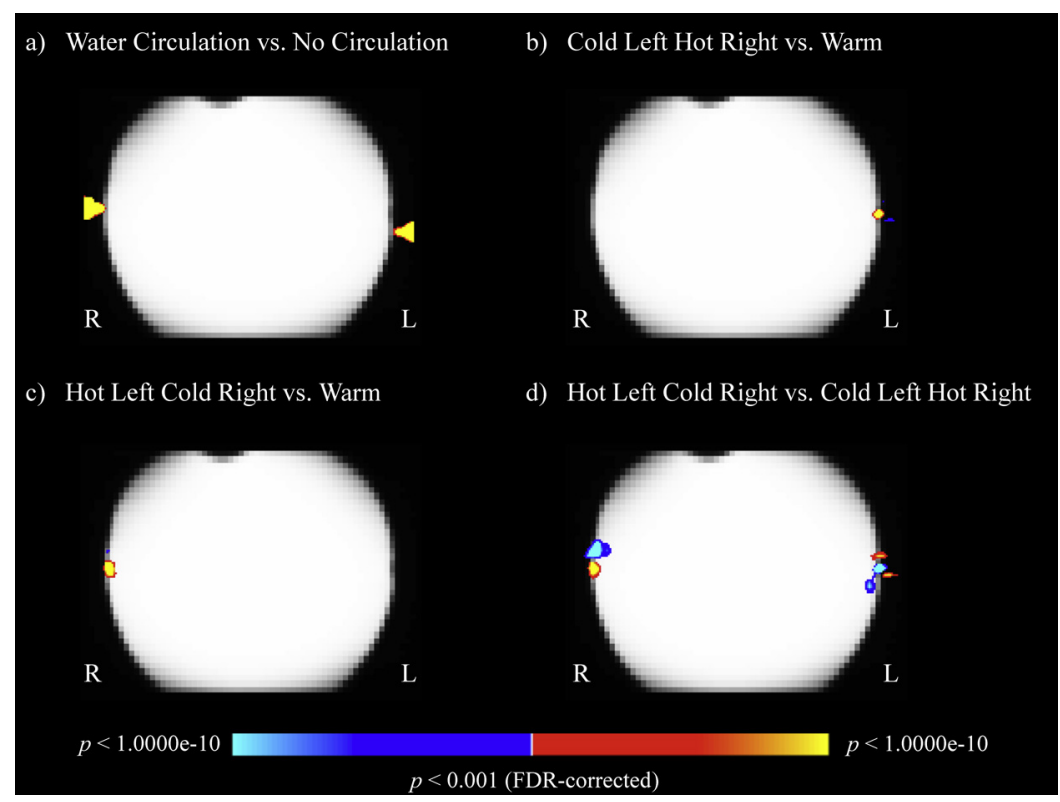

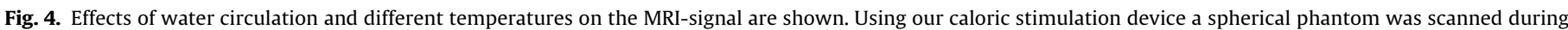

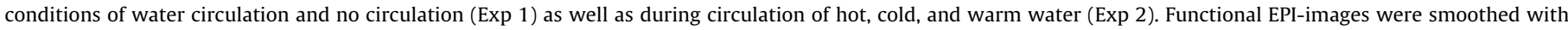

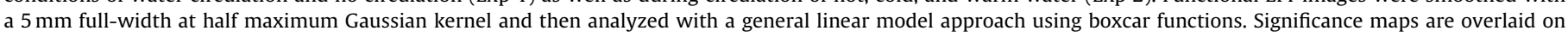

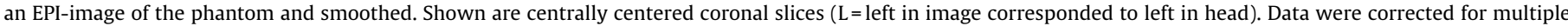

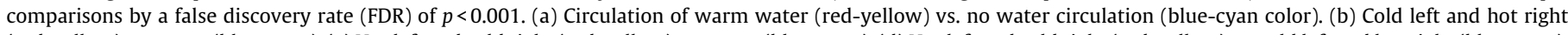

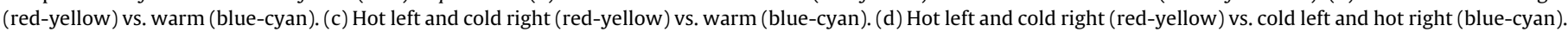
(For interpretation of the references to color in this figure legend, the reader is referred to the web version of the article.)

experiment 2 revealed that all three temperatures (hot, cold, and warm) led to distinguishable MRI-signals at the location of the pods (Fig. 4b-d). Overall, cold led to a stronger signal than warm or hot, both of which had rather similar effects on the MRI-signal (i.e. no difference when hot stimulation was contrasted with warm stimulation on either side, see Fig. 4b and c). However, when hot and cold were contrasted directly (Fig. 4d) clear signal differences emerged with again a stronger MR-signal for cold vs. hot. Importantly, each of these effects was restricted to the outer surface of the phantom and did not extend substantially into the inside area (i.e. the area that would contain the brain in a participant). Accordingly, we think it is unlikely that our device induces artifacts in the functional EPIimages of the brain. Small, temperature-dependent artifacts are, however, evident in the immediate vicinity of the stimulation pods and adjacent tubes.

\subsection{Caloric nystagmus}

Fig. 5 shows an example of eye-tracking data of a participant (P1) under conditions of vestibular stimulation in the dark without central fixation (top) and with fixation (bottom). Shown are trials (15 s long period with steady-state temperatures, see Fig. 3) during which participants reported self motion. Periods of nystagmus were most pronounced without central fixation and remarkably reduced when a fixation cross was presented (in the fMRI-experiment we always used a central fixation target). In these terms our results resemble those reported by Naito et al. (2003). In the example selfmotion trial without fixation we stimulated with hot left and cold right. The participant reported self motion to the left. The slowphase of the horizontal nystagmus was to the right, i.e. ipsilateral to the side of cold-water stimulation. This control measurement indicates that under our conditions with a central fixation cross (vestibular fMRI-experiment), we expect less pronounced nystagmus eye-movements in our participants during caloric stimulation.

\subsection{Vestibular stimulation FMRI-experiment}

Across participants we were able to use, on average, five self-motion trials $(S D=1.1)$, where predicted (because of caloric stimulation with hot in one ear and simultaneously cold in the other) and reported sensations of self motion matched. For the no self-motion, baseline condition (with warm in both ears), on average, 5.5 trials $(S D=1.1)$ per participant were included in the MRI-analysis. There was no significant difference in the number of modeled self-motion and no self-motion trials $(t(12)=-0.72$, $p=0.49$ ).

Fig. 6 shows the activation for the contrast self motion vs. no self motion in a surface-based random effects analysis overlaid on inflated left and right hemispheres of the Freesurfer template brain. Sensations of self motion evoked by CVS were associated in the right hemisphere with activity in putative PIVC. In the left hemisphere dorsal parietal cortex was activated. Bilateral activation was also evident in supramarginal gyrus, frontal and supplementary frontal eye-fields, anterior/middle insula, and in the inferior frontal operculum. These results match closely to previously reported activations during vestibular stimulation (see Lopez and Blanke, 2011).

\section{Discussion}

We constructed a caloric stimulation device for MRI-compatible vestibular stimulation. The device can be operated manually and pumps hot, cold, and warm water to the left and/or right ear. A small glass pod transmits the temperature of the water to the skin surface of the ear canal before the water returns to a collecting barrel in the scanner control room. The change in temperature is predicted to stimulate primarily the horizontal semicircular vestibular canal in the bony labyrinth because of close vicinity to the ear canal. During bithermal stimulation with hot in one ear and cold in the other participants reliably perceived self motion as headrotation to the left or right. Eye-movement recordings revealed the 


\section{P1}
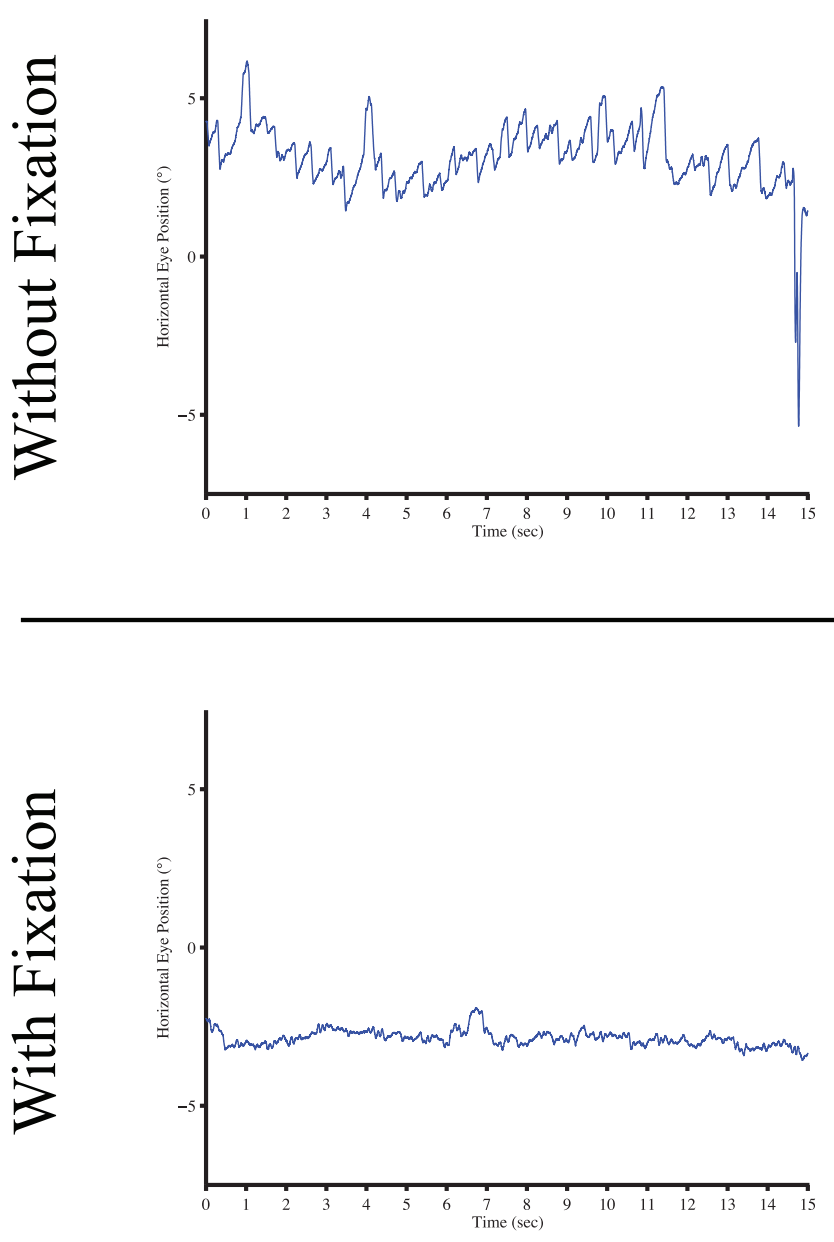

Fig. 5. Results of eye-movement recordings during vestibular stimulation under conditions without central fixation (top) and with fixation (bottom) are presented. The horizontal position of the right eye (in degrees visual angle) for one participant (P1) is depicted for $15 \mathrm{~s}$-long periods of steady-state temperatures (see gray shaded area in Fig. 3) in two trials with simultaneous self-motion sensation. Occasional vertical lines reflect blinks. Overall, nystagmus eye-movements were pronounced when no central fixation was provided.

presence of caloric nystagmus during stimulation when no central visual fixation mark was presented (Fig. 5).

Our selection of temperatures for the hot, cold and warm stimuli was carefully made to maximize the direction-specific sense of self motion (i.e. to the left or to the right), while the mixture of hot and cold for baseline trials led to few reports of self motion (see above). Obviously, the temperatures used in any given experiment will depend on many factors (e.g. stimulus duration, number of trial repeats, etc.) and should be carefully determined by the investigators. Each new set of temperatures should be calibrated using a thermal sensor in order to see how much temperatures change during transport from the water barrels to the ear pods. Also, when performing the stimulation in a room different from the room where the temperature calibration was conducted (e.g. calibration in the control room, stimulation in the MRI-scanner), the temperature of the two rooms should be closely matched. This is because the room temperature will have an influence on how much the temperatures differ between water barrel and pod.

Compared to regular caloric stimulation devices our system overcomes problems associated with water collection by using a closed-loop system where the water is collected outside the scanner and can be reused in later stimulation trials and/or experiments. Differences in the EPI-images emerged for water circulation and no circulation conditions (Lobel et al., 1998) and for the different temperatures used (Rieke and Butts Pauly, 2008). However, these effects were limited to the location of the stimulation pods and the influx and efflux tubes thus making intrusion of artifacts into the EPI-images of the brain unlikely. Our device can be used inside and outside the scanner environment. It allows for multiple, consecutive stimulation and baseline trials. Depending on the distance between the water barrels and the participant, a temporal gradient required until temperatures reach steady-state has to be taken into account. In our case with a distance of $\sim 10.5 \mathrm{~m}$ the interval was $10 \mathrm{~s}$. The temporal lag and plateau of hot, cold, and warm remained constant across different trials. The position of the stimulation pods can be adjusted easily inside the ear protection thus making stimulation possible with differently sized ears and ear canals. We used 30 s-long stimulation trials during which time approximately 0.51 of water circulated. The stimulation was kept short in order to avoid overstimulation of the vestibular system that would have evoked self-motion sensations outlasting the period of stimulation. The baseline trial in between two caloric stimulation trials could be prolonged (e.g. from 30 to $60 \mathrm{~s}$ ) in order to avoid slight variations in the baseline temperature due to preceding caloric stimulation with hot/cold and to allow the vestibular organ to reach steady-state levels. The distilled water can be stored and reused in later experiments. All components of the device are easy to construct. The raw material is inexpensive and was acquired off-the-shelf from a local hardware store. The pumps are made commercially for use in home aquariums. The glass pods used for temperature application in the ear canal were produced by a glassblower. Alternatively, they could be manufactured by shortening a thin-walled test tube to fit.

Vestibular stimulation during fMRI-scanning in 13 participants yielded a large cluster of activity deep in lateral sulcus of the right hemisphere. We assume this cluster of activation to be the putative human homologue of the core vestibular area PIVC in primates. A right-hemisphere dominance of the possible human PIVC is in line with previous findings (see Eickhoff et al., 2006; Lopez et al., 2012a; zu Eulenburg et al., 2012). Other cortical vestibular activations are in agreement with previous reports and support the validity of stimulation with our method.

In a few trials of the fMRI-experiment the reported subjective sensation did not match our expectation: participants indicated an absence of self motion during caloric stimulation or reported self motion during baseline. Failure to report self motion when caloric stimulation was performed might have happened because the perceived intensity of self motion was too low to surpass a subjective threshold. False positives, i.e. reported self motion during bilateral warm water (baseline) stimulation, might be the result of carry-over effects of a previous caloric stimulation trial. We think the exclusion of "error" trials makes our MRI-comparison between activity recorded during caloric and baseline more valid: only caloric stimulation trials are included where the sensation of self motion was above a certain threshold (in other words, trials where the vestibular response had a certain minimum intensity level). Results from these trials were compared to baseline trials where the vestibular system was not or only weakly stimulated leading to an absence of any self-motion percept.

Finally, we want to discuss some advantages and disadvantages of our device and, more generally, vestibular caloric stimulation. Our device is low-cost and can be easily constructed and maintained. Components can be replaced and the system can be modified in order to achieve optimal stimulation for different conditions (e.g. patients vs. healthy participants, unilateral vs. bilateral stimulation, variable distances between control room and participant in the scanner). The temperature stimulus is mild and not 


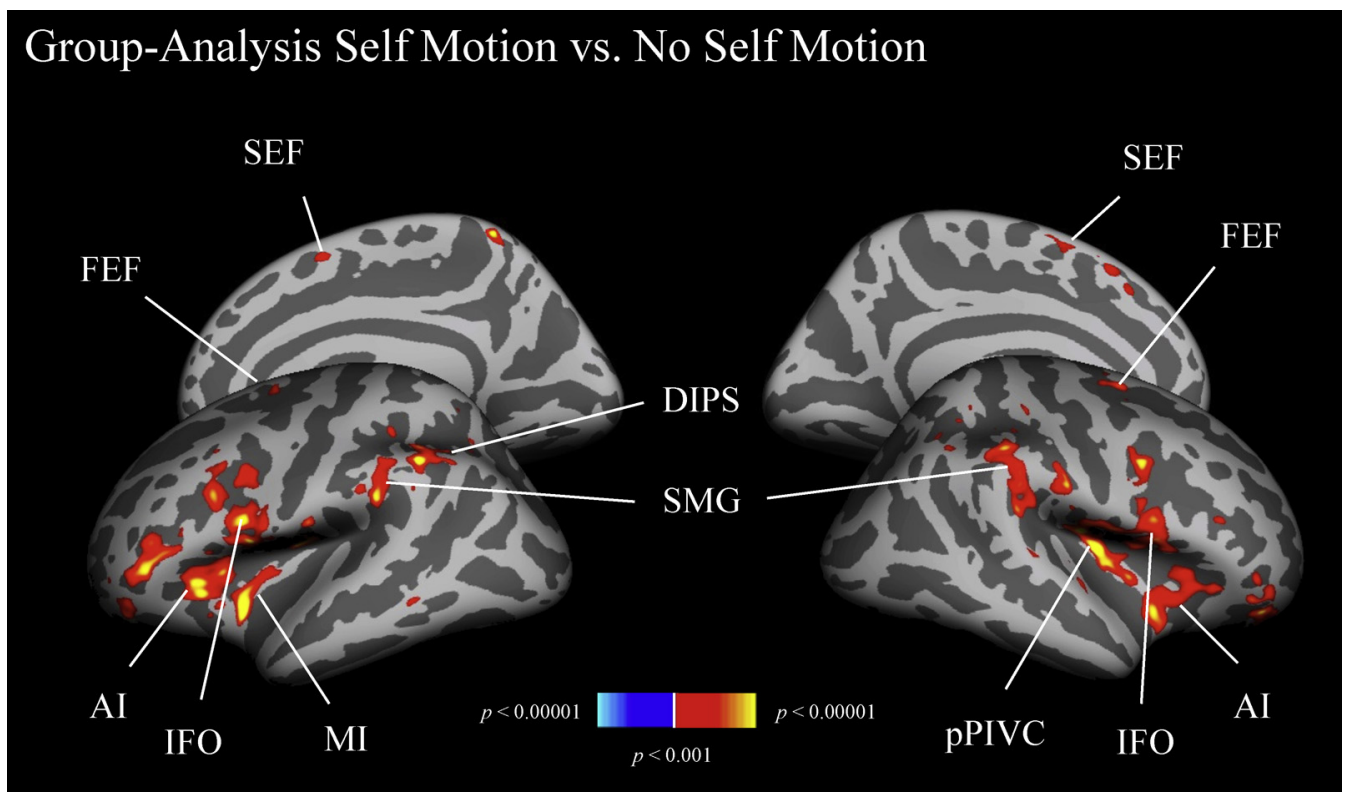

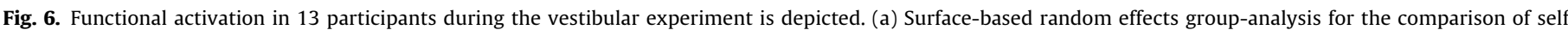

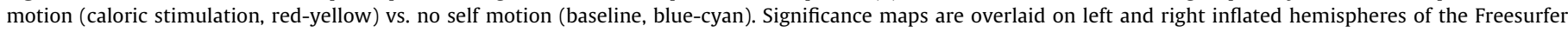

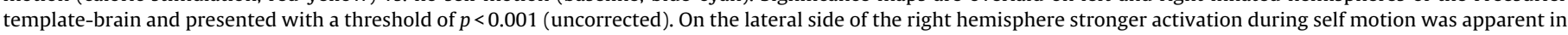

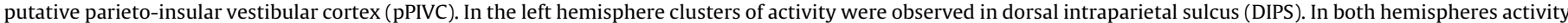

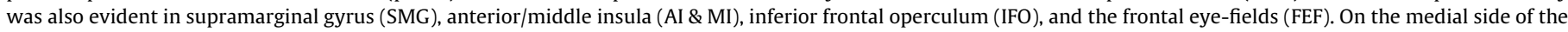

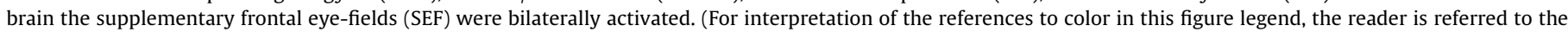
web version of the article.)

perceived as painful making our system suitable for application with patients and healthy participants. In addition, caloric stimulation elicits clear sensations of rotation (especially in the roll- and yaw-planes) to the left or right dependent upon the side of the hot and cold stimuli. Our participants described self motion as rotation away from the side of cold stimulation toward the side of hot stimulation (see also Fasold et al., 2002). That makes our system and caloric stimulation suitable for the combination with visual stimuli (Deutschländer et al., 2002; Frank et al., submitted for publication). Sensations of rotational self-motion to the left or right due to caloric stimulation can be combined with coherent visual motion either in the same or different directions in order to create conditions of congruent and incongruent visual-vestibular interactions (Frank et al., submitted for publication; see also Loose et al., 1999 and Probst et al., 1995, for a similar approach but with inertial motion of a platform for vestibular stimulation). Thus, our caloric device can be used to examine conditions of combined visual and vestibular stimuli where the directions of visual and vestibular motion are comparable and can be modulated by the experimenter. A delay until temperatures are at steady-state (with our setup: $\sim 10 \mathrm{~s}$ ) has to be taken into account in the design of such visual-vestibular interaction experiments. During that delay $100 \%$ random visual motion could be presented, which then switches to e.g. $90 \%$ random motion with $10 \%$ coherent motion intermixed (Frank et al., submitted for publication).

However, our device and caloric stimulation in general have also drawbacks: our system requires a temporal gradient before the temperatures are at stable states and constant vestibular stimulation is provided. Thus, it is only suitable for fMRI block-designs, which are much slower than popular and more efficient eventrelated imaging protocols. Galvanic stimulation, on the other hand, leads to instantaneous stimulation of the vestibular system and is better suited for (fast) event-related fMRI-designs (see Smith et al., 2012, for an example). A disadvantage of galvanic stimulation is that other sensory systems are electrically co-stimulated to some extent (e.g. leading to a pricking pain behind the ears or to faint auditory sensations; Lopez et al., 2012a), which is absent in caloric stimulation. In galvanic stimulation tactile stimulation can occur at the electrode site, whereas in caloric stimulation thermosensors in the ear canal are co-stimulated. Thus, in both methods activity especially in somatosensory cortex might be evoked that is not due to vestibular stimulation but due to stimulation of other sensory systems.

In conclusion we suggest that our caloric stimulation device can be recommended particularly for use in sensitive participant groups (including patients where vestibular functioning should be tested) and in studies where the interaction between the vestibular and visual (or other sensory) systems is examined. In those circumstances our new caloric stimulation device becomes an efficient and convenient method for vestibular stimulation especially during fMRI-scanning or other types of functional brain imaging.

\section{Acknowledgments}

We are especially grateful to Christian Renner for construction, technical support, and maintenance of the caloric stimulation system. In addition, we thank Peter Fuchs for technical assistance in the physical temperature measurements. We also wish to thank two anonymous reviewers for helpful comments on a previous version of the manuscript. The authors were supported by Deutsche Forschungsgemeinschaft (GR988/20-2).

\section{References}

Anderson S. Caloric irrigators: air, open-loop water and closed-loop water. $\mathrm{Br}$ J Audiol 1995;29:117-28.

Bárány R. Physiologie und Pathologie des Bogengangapparates beim Menschen. Leipzig: Franz Deutsche-Verlag; 1907.

Barnes GR. Adaptation in the oculomotor response to caloric irrigation and the merits of bithermal stimulation. Br J Audiol 1995;29:95-106.

Batuecas-Caletrio A, Montes-Jovellar L, Boleas-Aguirre MS, Perez-Fernandez N. The ice-water caloric test. Acta Otolaryngol (Stockh) 2009;129:1414-9, http://dx.doi.org/10.3109/00016480902791686.

Brandt T, Strupp M. General vestibular testing. Clin Neurophysiol 2005;116:406-26. 
Britten KH. Mechanisms of self-motion perception. Annu Rev Neurosci 2008;31:389-410, http://dx.doi.org/10.1146/annurev.neuro.29.051605. 112953.

Cardin V, Smith AT. Sensitivity of human visual and vestibular cortical regions to egomotion-compatible visual stimulation. Cereb Cortex 2010;20:1964-73, http://dx.doi.org/10.1093/cercor/bhp268.

Chen A, DeAngelis GC, Angelaki DE. Macaque parieto-insular vestibular cortex: responses to self-motion and optic flow. J Neurosci 2010;30:3022-42, http://dx.doi.org/10.1523/JNEUROSCI.4029-09.2010.

Cox RW, Jesmanowicz A. Real-time 3D image registration for functional MRI. Magn Reson Med 1999:42:1014-8.

Dale AM, Fischl B, Sereno MI. Cortical surface-based analysis. I. Segmentation and surface reconstruction. Neuroimage 1999;9:179-94.

DeAngelis GC, Angelaki DE. Visual-vestibular integration for self-motion perception. In: Murray MM, Wallace MT, editors. The neural bases of multisensory processes. Boca Raton, FL: CRC Press; 2012 [Chapter 31]

Deutschländer A, Bense S, Stephan T, Schwaiger M, Brandt T, Dieterich M. Sensory system interactions during simultaneous vestibular and visual stimulation in PET. Hum Brain Mapp 2002;16:92-103.

Dieterich M, Bense S, Lutz S, Drzezga A, Stephan T, Bartenstein P, et al. Dominance for vestibular cortical function in the non-dominant hemisphere. Cereb Cortex 2003;13:994-1007, http://dx.doi.org/10.1093/brain/awn042.

Dieterich M, Brandt T. Functional brain imaging of peripheral and central vestibular disorders. Brain 2008;131:2538-52.

Eickhoff SB, Weiss PH, Amunts K, Fink GR, Zilles K. Identifying human parieto-insular vestibular cortex using fMRI and cytoarchitectonic mapping. Hum Brain Mapp 2006;27:611-21, http://dx.doi.org/10.1002/hbm.20205.

Falconer CJ, Mast FW. Balancing the mind: vestibular induced facilitation of egocentric mental transformations. Exp Psychol 2012;59:332-9.

Fasold O, von Brevern M, Kuhberg M, Ploner CJ, Villringer A, Lempert T, et al. Human vestibular cortex as identified with caloric stimulation in functional magnetic resonance imaging. Neuroimage 2002;17:1384-93.

Fischl B, Sereno MI, Dale AM. Cortical surface-based analysis. II: Inflation, flattening, and a surface-based coordinate system. Neuroimage 1999;9:195-207.

Frank SM, Baumann O, Mattingley JB, Greenlee MW. Vestibular and visual responses in human posterior insular cortex; 2014 [submitted for publication].

Grüsser OJ, Pause M, Schreiter U. Localization and responses of neurones in the parieto-insular vestibular cortex of awake monkeys (Macaca fascicularis). J Physiol 1990;430:537-57.

Guldin WO, Grüsser OJ. Is there a vestibular cortex. Trends Neurosci 1998;21:254-9.

Lobel E, Kleine JF, Bihan DL, Leroy-Willig A, Berthoz A. Functional MRI of galvanic vestibular stimulation. J Neurophysiol 1998;80:2699-709.

Loose R, Ayan T, Probst T. Visual motion direction evoked potentials are direction specifically influenced by concurrent vestibular stimulation. Clin Neurophysiol 1999;110:192-9.
Lopez C, Blanke O. The thalamocortical vestibular system in animals and humans. Brain Res Rev 2011;67:119-46, http://dx.doi.org/10.1016/j.brainresrev.2010.12.002.

Lopez C, Blanke O, Mast FW. The human vestibular cortex revealed by coordinate-based activation likelihood estimation meta-analysis. Neuroscience 2012a;212:159-79.

Lopez C, Schreyer H-M, Preuss N, Mast FW. Vestibular stimulation modifies the body schema. Neuropsychologia 2012b;50:1830-7.

Mast FW, Merfeld DM, Kosslyn SM. Visual mental imagery during caloric vestibular stimulation. Neuropsychologia 2006;44:101-9, http://dx.doi.org/10.1016/j.neuropsychologia.2005.04.005.

Naito Y, Tateya I, Hirano S, Inoue M, Funabiki K, Toyoda H, et al. Cortical correlates of vestibulo-ocular reflex modulation: a PET study. Brain 2003;126:1562-78, http://dx.doi.org/10.1093/brain/awg165.

Probst T, Loose R, Niedeggen M, Wist ER. Processing of visual motion direction in the fronto-parallel plane in the stationary or moving observer. Behav Brain Res 1995;70:133-44.

Rieke V, Butts Pauly K. MR thermometry. J Magn Reson Imaging 2008;27:376-90 http://dx.doi.org/10.1016/j.cub.2011.08.029.

Schlindwein P, Mueller M, Bauermann T, Brandt T, Stoeter P, Dieterich M. Cortical representation of saccular vestibular stimulation: VEMPs in fMRI. Neuroimage 2008;39:19-31, http://dx.doi.org/10.1016/j.neuroimage.2007.08.016.

Sled JG, Zijdenbos AP, Evans AC. A nonparametric method for automatic correction of intensity nonuniformity in MRI data. IEEE Trans Med Imaging 1998;17:87-97, http://dx.doi.org/10.1109/42.668698.

Smith AT, Wall MB, Thilo KV. Vestibular inputs to human motion-sensitive visual cortex. Cereb Cortex 2012;22:1068-77, http://dx.doi.org/10.1093/cercor/bhr179.

Stephan T, Deutschländer A, Nolte A, Schneider E, Wiesmann M, Brandt $\mathrm{T}$, et al. Functional MRI of galvanic vestibular stimulation with alternating currents at different frequencies. Neuroimage 2005;26:721-32, http://dx.doi.org/10.1016/j.neuroimage.2005.02.049.

Suzuki M, Kitano H, Ito R, Kitanishi T, Yazawa Y, Ogawa T, et al. Cortical and subcortical vestibular response to caloric stimulation detected by functional magnetic resonance imaging. Cognit Brain Res 2001;12:441-9.

Wuyts FL, Furman J, Vanspauwen R, Van de Heyning P. Vestibular function testing. Curr Opin Neurol 2007;20:19-24, http://dx.doi.org/10.1097/WCO.0b013e3280140808.

zu Eulenburg P, Caspers S, Roski C, Eickhoff SB. Meta-analytical definition and functional connectivity of the human vestibular cortex. Neuroimage 2012;60:162-9, http://dx.doi.org/10.1016/j.neuroimage.2011.12.032. 